\title{
Erratum
}

\section{Ann. Surg. Oncol., Vol. 12, No. 9, September 2005, pp. 705-711 (DOI: 10.1245/ASO.2005.08.020)}

In the article by Fan et al., entitled "The Effect of Sentinel Node Tumor Burden on Non-Sentinel Node Status and Recurrence Rates in Breast Cancer," an author's degree appeared incorrectly.

The list of authors and their degrees appears correctly as follows:

Yang-Guo Fan, MD, Yah-Yuen Tan, MD, Chen-Teng Wu, MD, Patrick Treseler, MD, Ying Lu, PhD, Chung-Wei Chan, BS, Shelley Hwang, MD, Cheryl Ewing, MD, Laura Esserman, MD, Eugene Morita, MD, and Stanley P. L. Leong, MD

Published online: September 5, 2005. 